Virginia Commonwealth University vCU Scholars Compass

2017

\title{
History of the Innovation of Damage Control for Management of Trauma Patients: 1902-2016
}

Derek J. Roberts

University of Calgary, Regional Trauma Program, Calgary

Chad G. Ball

University of Calgary, Regional Trauma Program, Calgary

David V. Feliciano

Indiana University

See next page for additional authors

Follow this and additional works at: http://scholarscompass.vcu.edu/surgery_pubs

Part of the Surgery Commons

Copyright (C) 2017 Wolters Kluwer Health, Inc. All rights reserved.

\section{Downloaded from}

http://scholarscompass.vcu.edu/surgery_pubs/30

This Article is brought to you for free and open access by the Dept. of Surgery at VCU Scholars Compass. It has been accepted for inclusion in Surgery Publications by an authorized administrator of VCU Scholars Compass. For more information, please contact libcompass@vcu.edu. 


\section{Authors}

Derek J. Roberts, Chad G. Ball, David V. Feliciano, Ernest E. Moore, Rao R. Ivatury, Charles E. Lucas, Timothy C. Fabian, David A. Zygun, Andrew W. Kirkpatrick, and Henry T. Stelfox 


\title{
History of the Innovation of Damage Control for Management of Trauma Patients: 1902-2016
}

\author{
Derek J. Roberts, MD, PhD, ${ }^{*} \dagger$ Chad G. Ball, MD, MSc, ${ }^{*} \dagger \ddagger$ David V. Feliciano, MD, $\S$ Ernest E. Moore, MD, $\uparrow$ \\ Rao R. Ivatury, MD, \| Charles E. Lucas, MD, ${ }^{* *}$ Timothy C. Fabian, MD, †† David A. Zygun, MD, MSc, $\ddagger$

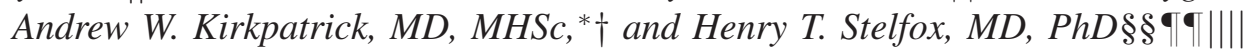

\begin{abstract}
Objective: To review the history of the innovation of damage control (DC) for management of trauma patients.

Background: DC is an important development in trauma care that provides a valuable case study in surgical innovation.

Methods: We searched bibliographic databases (1950-2015), conference abstracts (2009-2013), Web sites, textbooks, and bibliographies for articles relating to trauma DC. The innovation of DC was then classified according to the Innovation, Development, Exploration, Assessment, and Long-term study model of surgical innovation.

Results: The "innovation" of DC originated from the use of therapeutic liver packing, a practice that had previously been abandoned after World War II because of adverse events. It then "developed" into abbreviated laparotomy using "rapid conservative operative techniques." Subsequent "exploration" resulted in the application of DC to increasingly complex abdominal injuries and thoracic, peripheral vascular, and orthopedic injuries. Increasing use of DC laparotomy was followed by growing reports of postinjury abdominal compartment syndrome and prophylactic use of the open abdomen to prevent intra-abdominal hypertension after DC laparotomy. By the year 2000, DC
\end{abstract}

From the *Department of Surgery, University of Calgary, Calgary, Alberta, Canada; $†$ Regional Trauma Program, Calgary, Alberta, Canada; $†$ Departmen of Oncology, University of Calgary and the Foothills Medical Centre, Calgary, Alberta, Canada; §Department of Surgery, Indiana University Medical Center, Indianapolis, IN; - Department of Surgery, University of Colorado Denver, Denver, CO; ||Department of Surgery, Virginia Commonwealth University, Richmond, VA; **Department of Surgery, Wayne State University, Detroit, MI; ††Department of Surgery, University of Tennessee Health Science Center, Memphis, TN; $₫ \pm$ Division of Critical Care Medicine, University of Alberta, Edmonton, Alberta, Canada; §§Department of Critical Care Medicine, University of Calgary and the Foothills Medical Centre, Calgary, Alberta, Canada; - Department of Medicine, University of Calgary, Calgary, Alberta, Canada; and ||||Department of Community Health Sciences, University of Calgary, Calgary, Alberta, Canada.

Disclosure: This study was supported by an Alberta Innovates-Health Solutions Clinician Fellowship Award, a Knowledge Translation Canada Strategic Training in Health Research Fellowship, a Knowledge Translation Canada Research Stipend, and funding from the Canadian Institutes of Health Research. These funders had no role in the design or conduct of the study; collection, management, analysis, or interpretation of the data; or preparation, review, or approval of the manuscript. R.R.I. has received funding for consultancy and providing lectures from Kinetic Concepts Incorporated, whereas A.W.K. has received funding from Kinetic Concepts Incorporated for a randomized controlled trial comparing the ABThera Open Abdomen Negative Pressure Therapy System and Barker's vacuum pack temporary abdominal closure techniques. A.W.K. has also received travel funding from LifeCell Corporation, Syntheses, and Innovative Trauma Care. The other authors have no conflicts of interest to declare.

Supplemental digital content is available for this article. Direct URL citations appear in the printed text and are provided in the HTML and PDF versions of this article on the journal's Web site (www.annalsofsurgery.com)

Reprints: Derek J. Roberts, MD, PhD, Department of Surgery, University of Calgary, 10th Floor North Tower, Foothills Medical Centre, 1403-29th Street Northwest, Calgary, AB T2N 2T9, Canada.

E-mail: Derek.Roberts01@gmail.com.

Copyright (c) 2016 Wolters Kluwer Health, Inc. All rights reserved.

ISSN: 0003-4932/16/26505-1034

DOI: $10.1097 /$ SLA.0000000000001803 surgery had been widely adopted and was recommended for use in surgical journals, textbooks, and teaching courses ("assessment" stage of innovation). "Long-term study" of DC is raising questions about whether the procedure should be used more selectively in the context of improving resuscitation practices.

Conclusions: The history of the innovation of DC illustrates how a previously abandoned surgical technique was adapted and readopted in response to an increased understanding of trauma patient physiology and changing injury patterns and trauma resuscitation practices.

Keywords: abbreviated surgery, damage control, history, staged procedures, surgical innovation, wounds and injuries

(Ann Surg 2017;265:1034-1044)

T rauma damage control (DC) is a strategy for management of injured patients that includes DC surgery and DC resuscitation. DC surgery is most often used to control exsanguinating hemorrhage and/or gross contamination in patients with severe physiological derangements or high-risk injury patterns. ${ }^{1}$ After operation, the patient is admitted to the intensive care unit (ICU) for ongoing resuscitation before undergoing additional surgery. ${ }^{1} \mathrm{DC}$ resuscitation is a new concept characterized by rapid hemorrhage control, permissive hypotension, administration of blood products in a ratio approximating whole blood, and minimal use of crystalloid fluids. ${ }^{2}$

DC is an important development in trauma care and surgery from the latter decades of the last century that provides a valuable case study in surgical innovation. DC changed the age-old surgical dogma that all surgical procedures should be completed before leaving the operating room as it focused on limiting and/or treating deranged physiology before restoring normal anatomy. Its innovation was greatly influenced by the identification of coagulopathy as a principal cause of death in exsanguinating trauma patients and the evolution of trauma resuscitation practices. Its principles have now been used to reshape the practice of other civilian surgical subspecialties, military surgery, and trauma resuscitation itself. In this article, we review the history of the innovation of trauma DC.

\section{METHODS}

During the conduct of a scoping review, ${ }^{1,3}$ we searched 11 bibliographic databases (1950-March 1, 2015), abstracts from 5 conferences held between 2009 and 2013, 12 trauma Web sites, Google Scholar, and 30 trauma and surgery textbooks. One author (D.J.R.) selected all articles relating to the innovation of DC surgery and abbreviated surgical (or DC) techniques. This author also reviewed bibliographies of all selected articles and relevant review articles identified during the search. We defined DC surgery as a "multi-step operative intervention, which included a brief initial surgical procedure that aimed to control mechanical bleeding, a massive air leak, and/or gross contamination." 1,3 
The innovation of DC was classified according to the 5 stages of the Innovation, Development, Exploration, Assessment, and Long-term study (IDEAL) model of surgical innovation. ${ }^{4,5} \mathrm{We}$ defined an innovative surgical procedure according to the Society of University Surgeons as a "new or modified surgical procedure that differs from current accepted local practice, the outcomes of which have not been described, and which may entail risk to the patient." 6 The resultant summary was then sent to 5 senior surgeons (D.V.F., E.E.M., R.R.I., C.E.L., and T.C.F.) who were asked to identify additional references, provide personal reflections and historical photographs, and clarify DC historical events and innovation stages.

\section{History of the Innovation of DC (1902-2016)}

Table 1 provides a summary of the IDEAL model stages and principal events that occurred during the innovation of DC. Below, we describe how the "innovation" of DC originated from staged laparotomy for therapeutic liver packing and then "developed" into abbreviated laparotomy using rapid conservative operative techniques. We then detail how subsequent "exploration" resulted in the application of DC to increasingly complex abdominal injury patterns and injuries outside of the abdomen. Subsequently, we describe how increasing indications for and use of DC laparotomy was followed by growing reports of postinjury abdominal compartment syndrome (ACS) and prophylactic use of the open abdomen to prevent intra-abdominal hypertension (IAH) after DC laparotomy. Finally, we describe the current, "long-term study" stage of the innovation of DC, which is characterized by questions about whether DC surgery should be used more selectively in the current era of improving resuscitation practices (ie, DC resuscitation).

\section{Stage 1: Innovation (1902-1983)_Staged Laparotomy for Hepatic and Intra-abdominal Hemorrhage}

DC originated from the use of therapeutic packing to control hepatic hemorrhage. In contrast to resuscitative packing (where packs are used to check intraoperative bleeding for a short period of time), therapeutic packing refers to the prolonged (intra- and postoperative) use of packs to tamponade hemorrhage. ${ }^{1}$

In the early 1900s, before and after World War I, hepatorrhaphy with deep mattress sutures, gauze packing, and open drainage were commonly used to manage liver injuries. ${ }^{7,8}$ Pringle reported managing a difficult-to-access injury to the right hepatic lobe with suprahepatic packing in $1902 .{ }^{9}$ He subsequently concluded that "[t]he permanent arrest of hepatic hemorrhage is, in my opinion, best effected by ligation of the liver tissue in mass in every case where that is possible, but in some cases it may not be practicable and then we will have to rely solely upon packing." 9

Most surgical texts published during the early 1900s recommended that gauze packs be stuffed directly into hepatic tears to facilitate hemostasis (sometimes with the parenchyma loosely approximated overtop, creating a "tampon"). ${ }^{8,10,11}$ These "intrahepatic" packs would commonly be removed days later at the bedside. ${ }^{12,13}$ As packs frequently became adherent to the raw hepatic parenchyma, removal was associated with significant pain and often led to recurrent hemorrhage. ${ }^{11}$

Experiences using intrahepatic packing in a large number of trauma patients during World War II led Madding, Kennedy, and other members of the Second Auxillary Surgical Group to condemn its use by the end of the war. ${ }^{14,15}$ In 1971, Madding and Kennedy reported that: "[d]isastrous hemorrhage followed the removal of gauze packs. Abscesses occurred within the liver or in the perihepatic spaces, and hepatic necrosis was observed in areas that had been packed. Peritonitis, hepatitis, fistulas, and numerous other complications followed." 8 Therapeutic intrahepatic packing was therefore largely abandoned during the Korean and Vietnam wars, ${ }^{15}$ during which time many surgeons viewed its use as a sign of poor surgical skills. Most surgeons instead attempted to control hepatic hemorrhage using simple (eg, hepatorrhaphy) or advanced (eg, hepatotomy with selective vascular ligation, selective hepatic artery ligation, wedge resection, and/or segmentectomy or lobectomy) methods of mechanical hemostasis..$^{13,15-20}$ These and other improvements in management of these patients were associated with a reduction in hepatic trauma-related mortality from $66 \%$ in World War I to $9 \%$ in the Vietnam war. ${ }^{21}$

The use of therapeutic liver packing was resurrected in the late 1970s when new, yet limited indications for its use were suggested by Lucas and Ledgerwood. ${ }^{15,20}$ In a study of 637 patients undergoing operation for liver injuries at the Detroit General Hospital between 1968 and 1973, the authors reported using therapeutic "perihepatic" packing in 3 patients. ${ }^{20}$ One had an abdominal gunshot wound resulting in a trough along the anterior margin of both hepatic lobes, and the other 2 injuries requiring extension of the incision into the right chest. ${ }^{20}$ Packs were removed at reoperation 3 to 5 days later, and all patients survived. ${ }^{20}$ Lucas and Ledgerwood suggested that perihepatic packing had "a very important role for the temporary control of bleeding liver wounds which would otherwise require hepatectomy when the surgeon is not mentally or technically qualified to perform such a procedure." 20

Dr Alexander J. Walt, Chairman of the Department of Surgery at Wayne State University, later reported in 1978 that packing was effectively used to treat at least 5 patients with refractory hepatic hemorrhage in the preceding 15 years at the Detroit General Hospital. $^{22}$ Calne et $\mathrm{al}^{23}$ also reported that 4 patients presenting to peripheral hospitals in England with massive hepatic hemorrhage were successfully managed with conservative initial surgery and packing, which facilitated transfer to a definitive care center. In the Founder's Lecture presented at the 18th Annual Meeting of the Society for Surgery of the Alimentary Tract in 1977, Dr Walt addressed the widespread negative bias toward hepatic packing by stating: "I have no wish to revivify the idea of the pack as a desirable standard practice. On the other hand, the judicious surgeon who chooses this method should in no way fear the whispered loss of his surgical manhood." 22

Indications for perihepatic packing grew after nonmechanical (coagulopathic) hemorrhage was identified as the principal cause of death in patients undergoing operation for hepatic trauma. ${ }^{15}$ This complication was thought to occur because of massive transfusion of banked blood, disseminated intravascular coagulation, excessive fibrinolysis, platelet dysfunction, and/or defective synthesis of clotting factors. ${ }^{21,24}$ In 1978, Clagett and Olsen ${ }^{24}$ observed that $52 \%$ of patients with major liver trauma at Wayne County General Hospital developed coagulopathy. Elerding et $\mathrm{al}^{21}$ subsequently reported that coagulopathy was the cause of $82 \%$ of deaths following hepatic trauma at the Denver General Hospital and recommended routinely obtaining coagulation studies in these patients and prophylactic administration of plasma and platelets to patients receiving massive transfusion. ${ }^{21}$

In a subsequent publication, the Denver General group observed that exsanguinating hemorrhage was frequently associated with the onset of a "viscious cycle" (sometimes also referred to as the "bloody viscious cycle" or "lethal triad") of hypothermia, acidosis, and coagulopathy. ${ }^{25}$ They hypothesized that development of hypothermia and metabolic acidosis aggravated an already evolving coagulopathy. ${ }^{25-27}$ In retrospect, each of the elements of the viscious cycle were likely made worse by resuscitation practices at the time, including prompt administration of large volumes of crystalloid fluids to injured patients, a practice which was based on supportive preclinical experiments led by Shires in the 1960s. ${ }^{28,29}$ 


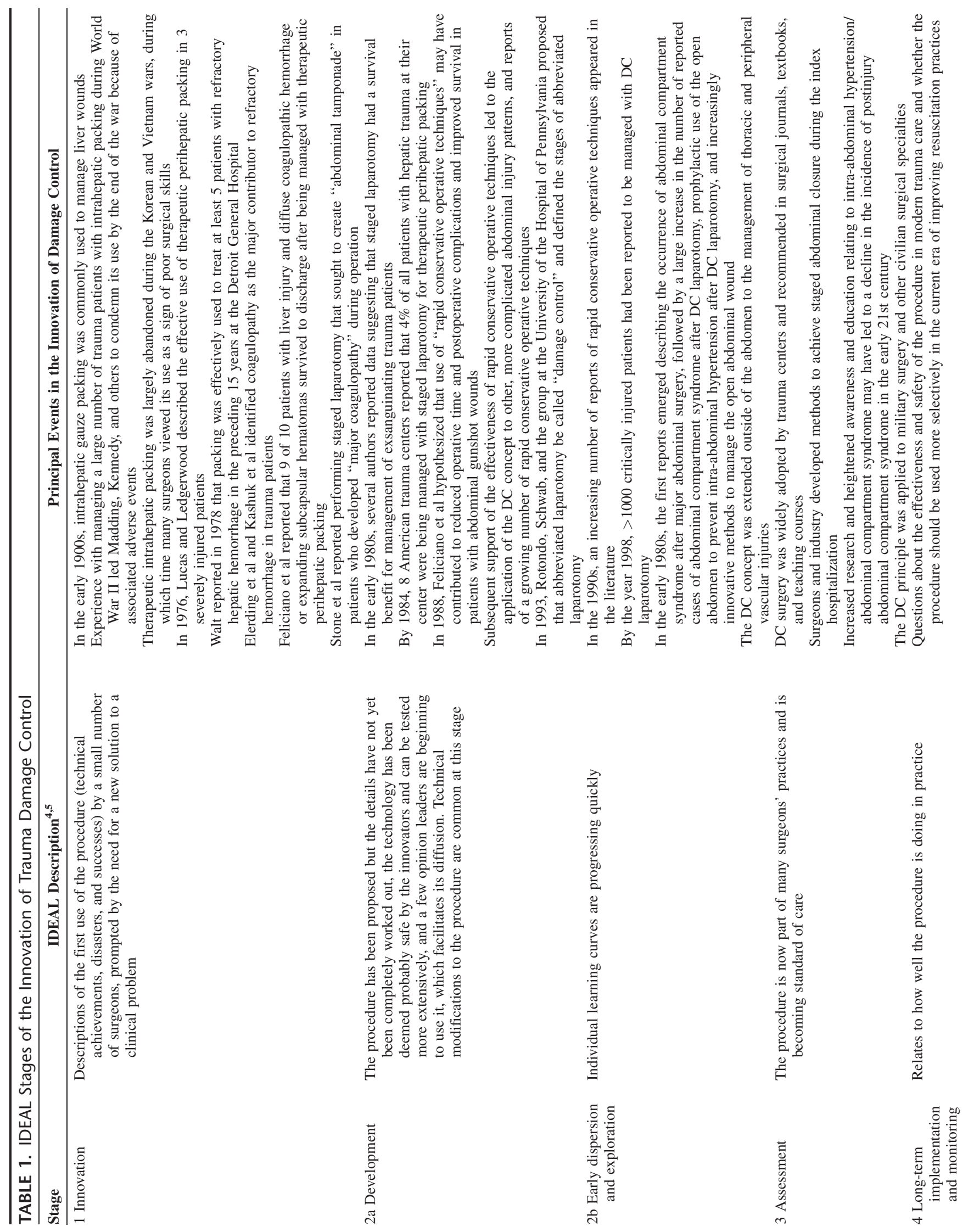




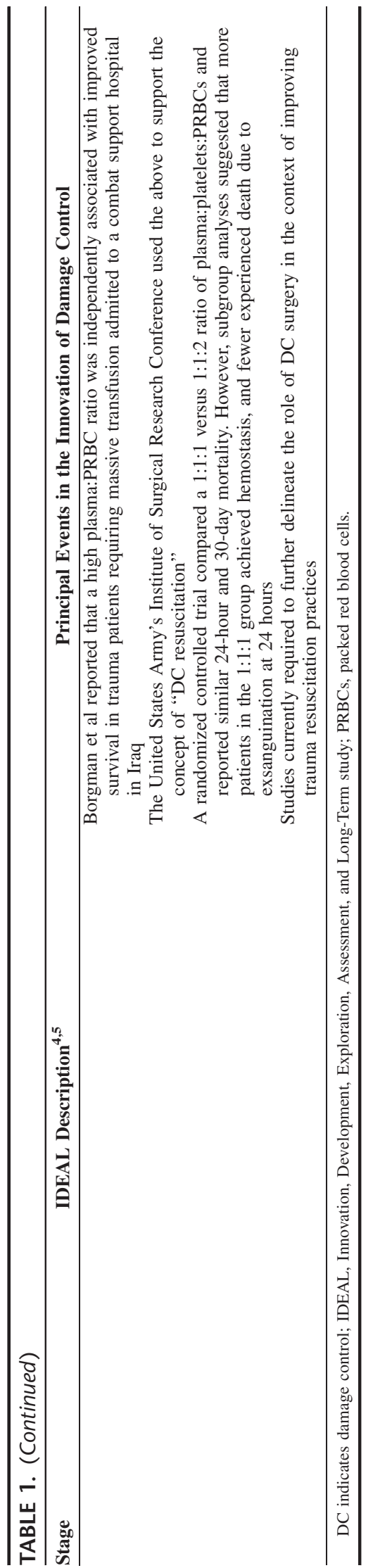

In 1981 , Feliciano et $\mathrm{al}^{13}$ reported that 9 of 10 patients at the Ben Taub General Hospital in Houston, TX, with major hepatic injuries and diffuse coagulopathic hemorrhage or expanding subcapsular hematomas survived to discharge after being managed with therapeutic perihepatic packing as a "last desperate maneuver." The authors suggested that therapeutic perihepatic packing may be a valuable adjunct for control of hepatic hemorrhage in highly selected patients who develop a coagulopathy after use of standard mechanical techniques of hepatic hemostasis. ${ }^{13}$ They also suggested that therapeutic perihepatic packing could be used instead of hepatic lobectomy to manage extensive subcapsular hematomas or bilobar parenchymal injuries. ${ }^{13}$

The final step of the innovation of DC surgery occurred at the Grady Memorial Hospital in Atlanta, GA, after Stone et $\mathrm{al}^{30}$ hypothesized that "the same principle [ie, compression] might prove to be effective even when a bleeding diathesis had led to a relatively diffuse hemorrhage throughout the entire peritoneal cavity." In 1979, these authors began performing staged laparotomy (ie, laparotomy with planned reoperation after a period of ongoing resuscitation in the ICU) that sought to create "abdominal tamponade" with packing in patients who developed "major coagulopathy" during operation. ${ }^{30}$ The protocol included: ". . .immediate termination of the operation; repair of only those vessels vital to survival, with ligation of all others; ligation of bowel ends. . . The spleen and kidney, if bleeding, were removed unless renal injury was bilateral, for which the kidneys were packed. Ureteral wounds were managed by simple ligation, while the bladder was closed with a one-layered purse-string suture. If the pancreas had been resected, the stump was ligated with an umbilical tape. Gallbladder wounds were closed by a purse-string suture, yet major bile duct injuries were merely isolated by laparotomy pack." 30 At the conclusion of abbreviated laparotomy, "an average of nine laparotomy pads (range of 4-17) then were packed tightly into the peritoneal cavity, and the abdomen was closed under considerable tension." 30 As compared to a historical survival estimate of $7 \%$ (1 of 14) among similarly injured patients managed "by standard procedures directed toward reversal of the bleeding diathesis plus completion of all details of the operative procedure", $65 \%$ (11 of 17) of patients survived when managed with staged laparotomy. ${ }^{30}$

\section{Stage 2a: Development (1984-1993)_Abbreviated Laparotomy Using Rapid Conservative Operative Techniques}

The subsequent stage of the innovation of DC included moving from a predominantly staged to an abbreviated laparotomy; the application of DC to other, more complicated abdominal injury patterns; and the proposal that the approach be called "damage control."

Use of staged laparotomy for management of trauma patients became widely accepted within 5 years of the publication by Stone et $\mathrm{al},{ }^{30}$ with several authors reporting supporting data. ${ }^{11,31-33}$ At the 1985 meeting of the American Association for the Surgery of Trauma (AAST), Drs Feliciano, Ivatury, Walt, and Pachter presented and discussed papers reporting on patients managed with therapeutic perihepatic packing at Ben Taub General Hospital and Lincoln Medical and Mental Health Center in the Bronx. ${ }^{11,32}$ They concluded that perihepatic packing was a potentially life-saving procedure for a small subset of patients with severe hepatic injuries when other methods failed to achieve hemostasis. ${ }^{32}$ The above findings initiated widespread practice change: by 1984, 8 American trauma centers reported that $4 \%$ (range, $0 \%-10 \%$ ) of all patients with hepatic trauma at their center were being managed with therapeutic perihepatic packing. ${ }^{34}$ 


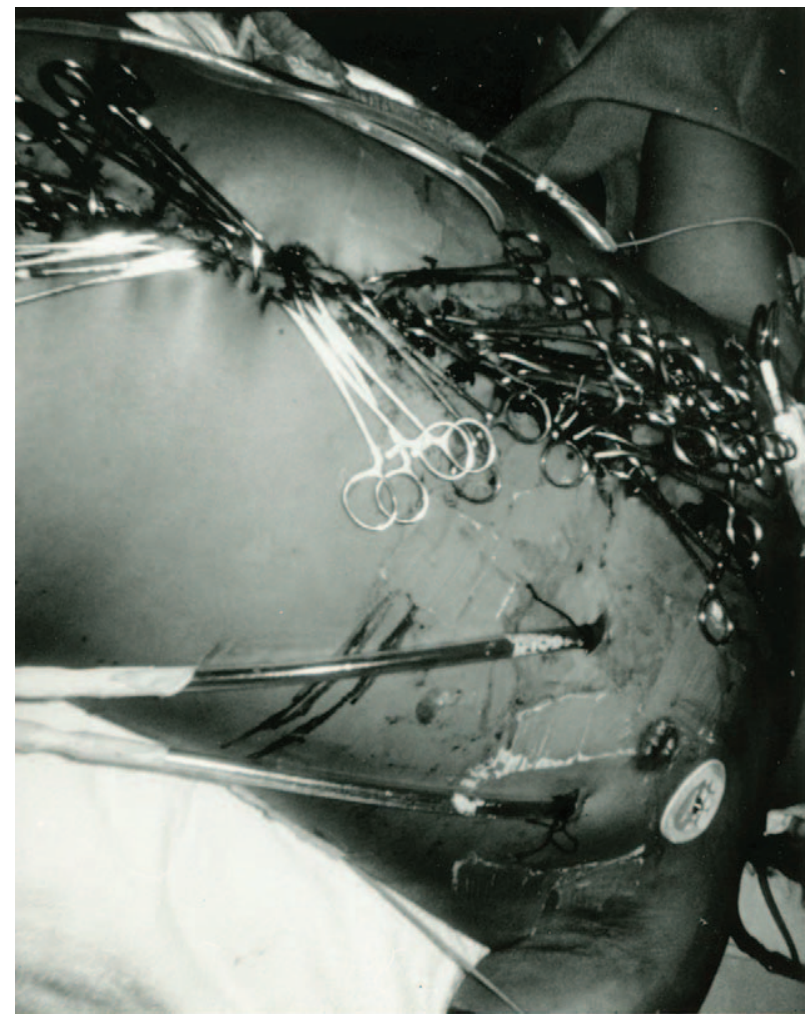

FIGURE 1. Temporary abdominal closure using towel clips. Reprinted with permission from ref. ${ }^{36}$ Copyright (1989), with permission from Elsevier.

Shortly thereafter, it was noted that staged laparotomy in critically injured patients might also improve outcomes by abbreviating the length of the index operation. ${ }^{35}$ In 1988, Feliciano et al ${ }^{35}$ described their experiences managing 300 consecutive patients with abdominal gunshot wounds using "rapid conservative operative techniques." These included nonresectional management of hepatic and splenic injuries, primary repair of small and large bowel injuries, rapid control of abdominal vascular injuries, and use of towel clips to quickly close the skin after operation in patients with hypothermia, non-mechanical bleeding, and/or marked abdominal visceral distention (Fig. 1)..$^{35,36}$ The authors hypothesized that abbreviated operative techniques may have contributed to reduced operative time and postoperative complications and improved survival during the study period. ${ }^{35}$

Support of the effectiveness of rapid conservative operative techniques led to the application of the DC concept to other abdominal injury patterns and reports of a growing number of abdominal DC interventions. In 1990, Eastlick et $\mathrm{al}^{37}$ reported managing a patient with an abdominal gunshot wound traversing the liver and destroying the pancreaticoduodenal complex with perihepatic packing and pancreaticoduodenectomy followed by reoperation for pancreaticobiliary and gastrointestinal reconstruction 36 hours later. Thereafter, Burch et $\mathrm{al}^{38}$ described using a number of "unorthodox" surgical techniques (ligation of enteric injuries, retained vascular clamps, and temporary intravascular shunting [TIVS]) among 200 critically injured patients admitted to Ben Taub General Hospital (Figs. 2 and 3). As $66(33.0 \%)$ of these patients survived, the authors suggested that prompt termination of laparotomy using abbreviated surgical techniques was a "rational approach to an apparently hopeless situation." 38

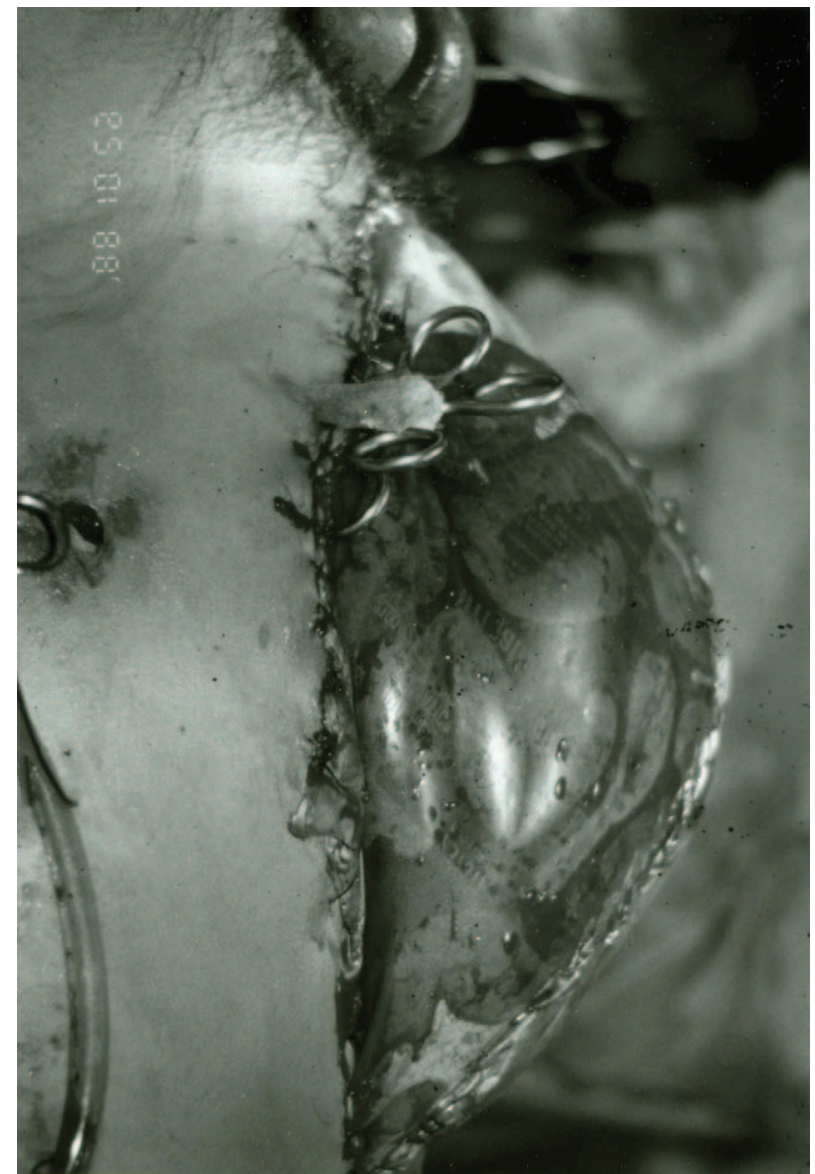

FIGURE 2. Temporary abdominal closure using a silo/Bogotá bag in a patient with retained vascular clamps on multiple pelvic bleeders after a transpelvic gunshot wound. Image reproduced with permission from ref. ${ }^{26}$ Copyright Elsevier (1991).

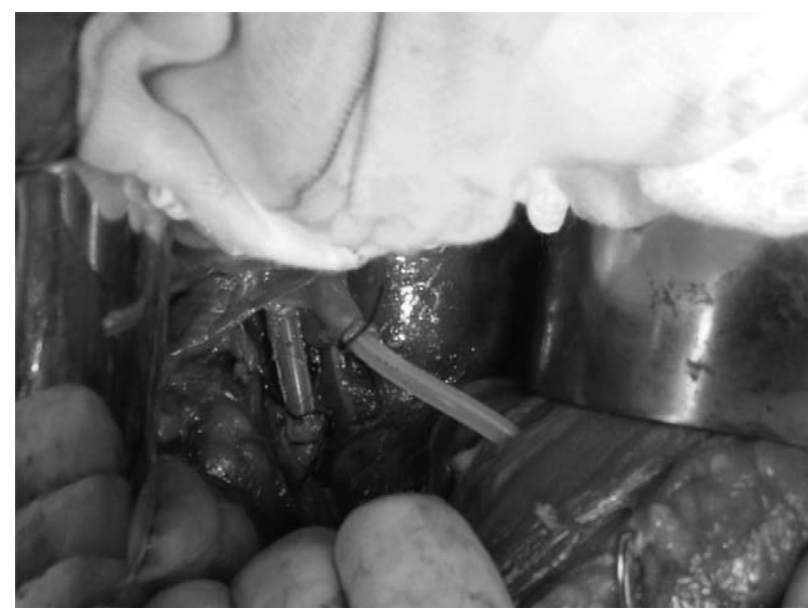

FIGURE 3. Temporary intravascular shunting of a combined iliac artery and ureter injury in a patient with an abdominal gunshot wound. 
The final step of the development of DC occurred in 1993 when Rotondo, Schwab, and the group at the Hospital of the University of Pennsylvania ${ }^{39}$ proposed that abbreviated surgery be called "damage control." They suggested that DC could have broad use given the increasing number of patients presenting to American trauma centers with multivisceral penetrating injuries from larger caliber, higher muzzle velocity, semiautomatic weapons. ${ }^{39-41}$ Schwab, a former officer in the US navy, adopted the term "damage control" from the navy where it represents "the capacity of a ship to absorb damage and maintain mission integrity," which, in trauma surgery, corresponds to "those maneuvers designed to ensure patient survival." 42,43 Surgeons at the University of Pennsylvania also more specifically defined the stages of abbreviated laparotomy as DC 1 (immediate laparotomy for control of hemorrhage and contamination followed by temporary abdominal closure [TAC] and transfer to the ICU), DC 2 (resuscitation in the ICU with the goal of maximizing hemodynamics and correcting hypothermia, acidosis, and coagulopathy), and DC 3 (reoperation for definitive repair of abdominal injuries and closure of the abdomen). ${ }^{39,44}$ These authors and others also later suggested adding the stages DC 0 or "damage control ground zero" (those interventions provided within the prehospital and trauma admissions area before operation) and DC IV (definitive abdominal reconstruction). ${ }^{45}$

\section{Stage $2 b$ (Part 1): Early Dispersion (1994-2000s)— The DC Laparotomy Learning Curve and Growing Reports of Postinjury Abdominal Compartment Syndrome}

In the early dispersion stage of the innovation of DC, increasing indications for and use of DC laparotomy were followed by growing reports of postinjury ACS, prophylactic use of the open abdomen to prevent IAH after DC laparotomy, and the development of increasingly innovative methods to manage the open abdominal wound.

This stage began with the development of new rapid conservative operative techniques. Hirshberg et $\mathrm{al}^{46}$ and the group at the Ben Taub General Hospital reported rapidly removing injured kidneys and using balloons to tamponade bleeding internal iliac vessels. ${ }^{46}$ Poggetti et $\mathrm{al}^{47}$ subsequently described using an improvised balloon tamponade device to control massive hemorrhage from bilobar transfixing hepatic gunshot wounds (Fig. 4). ${ }^{48}$ Reilly et al ${ }^{49}$ reported that a patient with complete transection of the proximal superior mesenteric artery, a nonviable-appearing midgut, and hypothermia, acidosis, and coagulopathy survived after TIVS was used to rapidly terminate operation and allow for rewarming and correction of coagulopathy in the ICU. ${ }^{49}$ Finally, Azimuddin et $\mathrm{al}^{50}$ and Coburn $^{51}$ suggested interventions that could be used to temporize injuries to the ureter and bladder, including delayed ureterouretostomy and unilateral and bilateral externalized ureteral stenting. By 1998 , there were reports of $>1000$ critically injured patients treated with DC laparotomy, of which an impressive $50 \%$ survived. ${ }^{52}$

In the early 1980s, the first reports emerged describing ACS after major abdominal surgery. Richards et $\mathrm{al}^{53}$ reported resolution of renal failure after laparotomy and evacuation of intra-abdominal hematomata in 4 postoperative patients with tense abdominal distention. Kron et $\mathrm{al}^{54}$ subsequently described that decompressing the abdomen in postoperative abdominal surgery patients with a bladder pressure $>25 \mathrm{~mm} \mathrm{Hg}$ seemed to reverse oliguric renal failure and prevent death. Finally, in 1989, Fietsam et al ${ }^{55,56}$ reported 4 patients who developed a condition that they termed "intra-abdominal compartment syndrome" (increased peak inspiratory and central venous pressures, oliguric renal failure, and massive abdominal distention) after repair of ruptured abdominal aortic aneurysms and administration of a massive volume of resuscitation fluids.

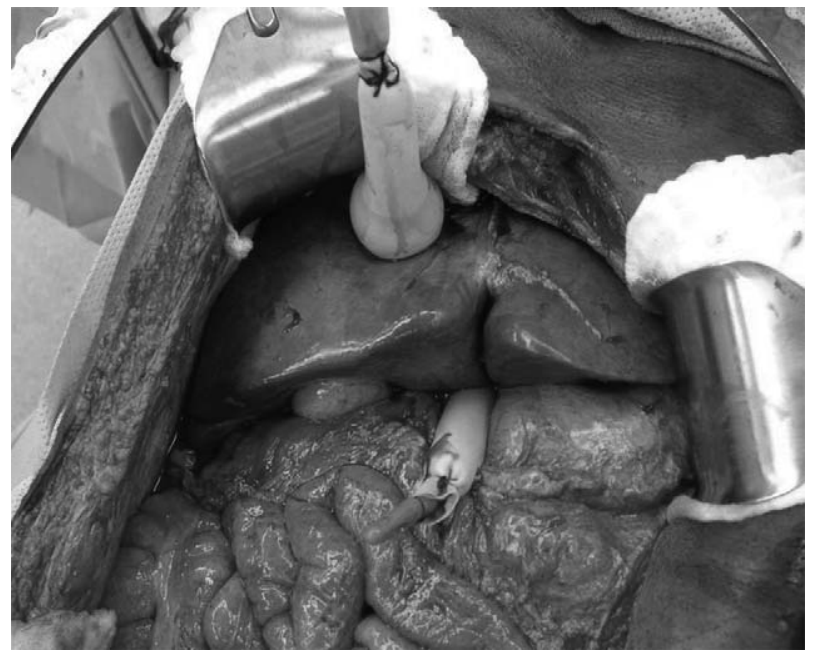

FIGURE 4. Penrose and red rubber Robinson catheter tamponade of a central hepatic gunshot wound. Image reproduced with permission from ref. ${ }^{48}$ Copyright Wolters Kluwer Health (2011).

The above was followed by reports of a large number of cases of ACS after DC laparotomy. ${ }^{56}$ Hemorrhagic shock was hypothesized to result in an ischemia-reperfusion injury of the bowel, increased intestinal permeability, and heightened sequestration of fluid in the bowel wall. ${ }^{57}$ This process, when combined with large volume fluid resuscitation and significant intra-abdominal blood/ ongoing intra-abdominal bleeding, tight intra-abdominal packing, and a tense, noncompliant abdominal wall, significantly increased intra-abdominal pressure. ${ }^{57,58}$ Forced closure of the skin and/or fascia in this setting (as was common at the time) was reported to frequently produce fascial necrosis and/or postoperative ACS. ${ }^{59,60}$ Some have hypothesized that the postinjury ACS epidemic was produced by resuscitation practices at the time that emphasized administration of large volumes of crystalloid fluids and use of supranormal trauma resuscitation in injured patients. ${ }^{56,61,62}$

To prevent postoperative ACS, studies appeared supporting the use of prophylactic abdominal decompression after abbreviated laparotomy. ${ }^{59,63,64}$ In 1993, Morris et $\mathrm{al}^{63}$ at Vanderbilt University recommended early abdominal decompression for patients who developed ACS after abbreviated laparotomy given the high mortality associated with the condition. At the 57th Annual Meeting of the AAST, Ivatury et $\mathrm{al}^{65}$ reported observing gastric mucosal acidosis in 70 critically ill patients with IAH who underwent abbreviated laparotomy at the Lincoln Medical \& Mental Health Center before the development of ACS. They hypothesized that, when left uncorrected, postoperative IAH may induce splanchnic hypoperfusion and gut mucosal acidosis resulting in ACS and therefore advocated for TAC of the "open abdomen" to prevent IAH/ACS after DC laparotomy. ${ }^{65}$

Original TAC methods provided "simple containment of the viscera." 66 Complications of the earlier method of towel clip closure included evisceration of small bowel (see Figure in Supplemental Digital Content 1, http://links.lww.com/SLA/B30) and postoperative ACS. ${ }^{26}$ Methods later used included bridging silos. ${ }^{26}$ Dr Oswaldo Borraez developed a commonly used temporary silo (the "Bogotá bag") while he was a surgical resident training in the Hospital San Juan de Dios in Bogotá, Colombia, South America. This silo commonly consists of a sterilized $3 \mathrm{~L}$ genitourinary irrigation bag cut at the seams, unfolded, and then anchored to the skin of the 

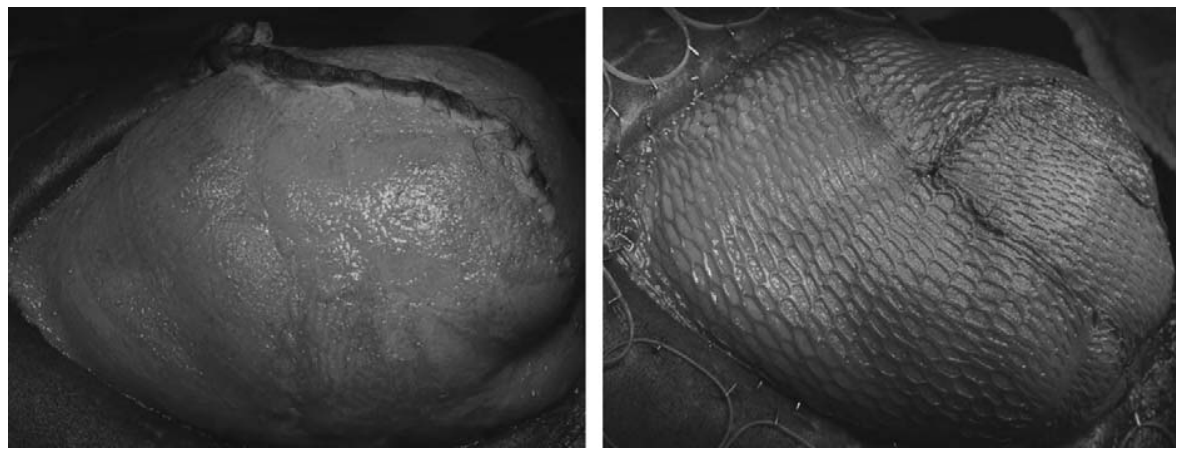

FIGURE 5. Use of a planned ventral hernia in a patient with secondary abdominal compartment syndrome after a ruptured descending thoracic aortic injury secondary to a motor vehicle collision. Appearance of the absorbable mesh prosthesis before its removal (left) and the subsequent application of a splitthickness skin graft to the granulated open abdomen (right). Images reproduced with permission from ref. ${ }^{71}$ Copyright McGraw-Hill Education (2000).

abdominal wound (see Figure in Supplemental Digital Content 2, http://links.lww.com/SLA/B30) ${ }^{67}$ Other simple TAC methods used included bridging absorbable or synthetic meshes, placement of a moist surgical towel over the viscera (covered by an adherent plastic drape over the skin), ${ }^{63}$ or a rayon cloth sheet/fluff gauze/retention suture "pack". ${ }^{68}$ Zippers and slide fasteners were also used in some centers for those requiring repeated abdominal exploration (see Figure in Supplemental Digital Content 3, http://links.lww.com/ SLA/B30).

If the abdominal wound was not closed within 10 to 15 days, dense adhesions developed between bowel loops and the undersurface of the abdominal wall, obliterating the intraperitoneal space and creating a "frozen abdomen." 66 This process, when combined with lateral retraction of the abdominal fascial edges, precluded definitive abdominal closure. These wounds were frequently managed with a "planned ventral hernia" after the report by Fabian et $\mathrm{al}^{69}$ at the University of Tennessee Health Science Center in 1994 (Fig. 5). ${ }^{70,71}$ In this technique, a temporary prosthesis (eg, polypropylene or polyglactin 910 mesh or expanded polytetrafluoroethylene) is sutured between the fascial edges to bridge the defect. ${ }^{69}$ This prosthesis is then removed 14 to 21 days later and the wound covered with a split-thickness skin graft or mobilized native skin flap. ${ }^{69}$ Finally, 6 to 12 months after hospital discharge, when the skin graft can be pinched off the underlying viscera, the graft is removed and the abdomen closed with a permanent prosthesis or components separation technique. ${ }^{69}$

In 1995, Brock, Barker, and Burns ${ }^{72}$ at the University of Tennessee College of Medicine described using a "vacuum pack" for TAC after DC laparotomy. This technique, which was a modification of that suggested by Schein et $\mathrm{al}^{73}$ in 1986 to manage intraabdominal sepsis, consisted of a visceral drape covered by surgical towels, 2 closed suction drains connected to wall suction, and an adhesive film dressing. The visceral drape served as a physical barrier that prevented adhesions between the bowel and abdominal wall, which extended the window of opportunity for definitive abdominal closure to as long as a month after initial operation. ${ }^{66}$ This relatively simple solution later allowed for creation of staged abdominal reconstruction techniques that could be used to achieve progressive abdominal closure during repeated laparotomies. ${ }^{66}$

\section{Stage $2 b$ (Part 2): Exploration (1994-2000s)- \\ Extension of the Concept Outside of the Abdomen}

The exploration stage of the innovation of DC was characterized by its adaptation to manage injuries outside of the abdomen, including those to the peripheral vasculature and thorax.

In the early 1990 s, before the promulgation of DC terminology, Feliciano et $\mathrm{ll}^{74}$ described using balloon catheters to effectively control life-threatening hemorrhage from cardiac and vascular wounds. This approach was later reported by Gilroy et al, ${ }^{75}$ Hirshberg et $\mathrm{al}^{46}$ and others ${ }^{76}$ to be effective for controlling a number of difficult-to-access bleeding sites in the trauma bay and/or the operating room. These include zone I and III of the neck; the face, pharynx, heart, and internal carotid artery at the base of the skull; and the innominate, axillary, subclavian, iliac, femoral, and popliteal vessels (Fig. 6). ${ }^{48}$

In 1994 , Scalea et $\mathrm{al}^{76}$ reported using DC to manage a patient with an extremity vascular injury at the SUNY Health Science Center in Brooklyn, NY. The patient presented with acidosis and coagulopathy after a stab wound produced brisk arterial bleeding from deep in the thigh that persisted despite attempts at surgical hemostasis. ${ }^{76}$ The wound tract was packed, the skin temporarily closed, and the patient transferred to the angiography suite for embolization of a branch of the profunda femoris artery. ${ }^{76}$ Others later described simple vascular repair techniques that could be used in hypothermic and coagulopathic patients with truncal and peripheral vascular injuries, including lateral repair, ligation, TIVS, and/or rapid primary amputation. $^{77}$

During the same year, Hirshberg et $\mathrm{al}^{46}$ described rapid measures to manage injuries in the chest. These included pleural cavity packing, nonanatomic pulmonary resections, and rapid lobectomy or pneumonectomy using linear stapling devices. ${ }^{46}$ Another thoracic DC intervention suggested as an alternative to anatomic

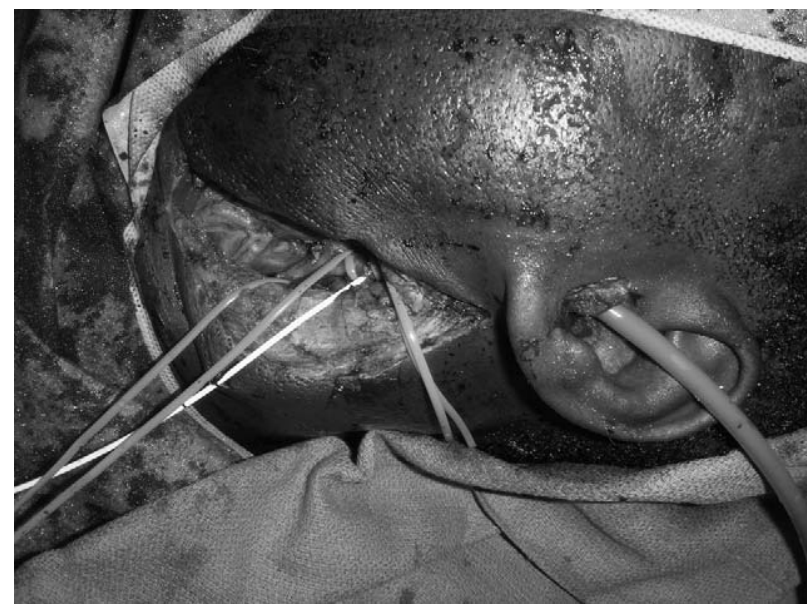

FIGURE 6. Foley and Fogarty balloon catheter tamponade of an internal carotid artery transection after a stab wound to the preauricular area of the face. Image reproduced with permission from ref. ${ }^{48}$ Copyright Wolters Kluwer Health (2011). 
lobectomy for patients with parenchymal lung bleeding was pulmonary tractotomy. ${ }^{78,79}$ In this technique, the lung overlying a pulmonary parenchymal wound is divided between vascular clamps or using a linear cutting stapler, thereby allowing small injured vessels and bronchi underneath to be selectively ligated. ${ }^{78,79}$ Other thoracic DC interventions that have been reported include simultaneously stapled pneumonectomy (as an alternative to conventional anatomic lobectomy $)^{80}$ and the pulmonary hilar twist (a 180-degree rotation of the pulmonary hilum to control hemorrhage and prevent air embolism after severe lung trauma requiring thoracotomy). ${ }^{81}$

\section{Stage 3: Assessment (Early 1990s-Late 2000s) _ Widespread Adoption of DC Surgery and Heightened Postinjury ACS Research, Education, and Preventive Efforts}

The assessment stage of the innovation of DC surgery was characterized by the widespread adoption and recommendation of the procedure in surgical journals, textbooks, and teaching courses; increased research, education, and awareness relating to IAH/ACS; the creation of methods to achieve definitive abdominal closure during the index hospitalization; and the application of the DC concept to military surgery and other civilian surgical specialties, including general, orthopedic, vascular, and neurological surgery.

In 2000, Scalea et $\mathrm{al}^{82}$ reported that DC had been "adopted by virtually every trauma center in this country" whereas in 2006 Sutton et $\mathrm{al}^{83}$ stated that "its overall benefit is indisputable." As many DCrelated complications stemmed from the inability to close the open abdominal wound, surgeons and industry developed methods that could be used to achieve staged abdominal reconstruction during the index hospitalization. These included the Wittmann patch (Starsurgical, Burlington, WI) ${ }^{64}$ negative pressure wound therapy devices, vacuum-assisted sequential fascial closure, ${ }^{84}$ vacuum-assisted wound closure and mesh-mediated fascial traction, ${ }^{85}$ and dynamic retention using sutures or the Abdominal Reapproximation Anchor device (Canica Design Inc, Almonte, Ontario, Canada).

By the early 2000s, the importance of postinjury ACS was well recognized. This stimulated formation of the World Society of the Abdominal Compartment Syndrome in 2004 (www.WSACS. org). Their reported goal was to "promote research, foster education, and improve the survival of patients with IAH and ACS." This group published expert consensus definitions in $2006,{ }^{86}$ clinical practice guidelines in $2007,{ }^{87}$ and recommendations for research in $2009 .{ }^{88}$ Some authors have hypothesized that increased research and heightened awareness and education relating to IAH/ACS have led to the decreased incidence of postinjury ACS observed in the last 15 years. $^{56}$

During this stage, the DC principle was also applied to military surgery and other civilian surgical specialties. In Operations Iraqi Freedom and Enduring Freedom in Afganistan, injured patients were transported by helicopter to a trauma facility in the combat zone after receiving battlefield treatment. ${ }^{89,90}$ At these facilities, resuscitative and stabilizing procedures, including intra-abdominal packing, rapid resection of bowel injuries, TIVS, and external fixation of long bone injuries, were completed before patients were transported to more advanced care locations. ${ }^{89-91}$ Scalea et al ${ }^{82}$ suggested in 2000 that external fixation of long bone fractures or "DC orthopedics" should be used instead of immediate intramedullary nailing in patients with multiple injuries. Pape et $\mathrm{al}^{92}$ subsequently reported that polytrauma patients with a femur fracture experienced a reduced postprocedure inflammatory burden when managed with external fixation instead of immediate intramedullary nailing. After further treatment at military trauma facilities, patients were transported to
Landstuhl Regional Medical Center in Germany. ${ }^{90}$ Through the Senior Visiting Surgeon Program (of the AAST and American College of Surgeons' Committee on Trauma), many civilian trauma care leaders in the United States volunteered to participate in the care of injured soldiers and contribute to education at the center, including about the principles and practice of DC. ${ }^{90}$

\section{Long-term Implementation and Monitoring (Late 2000s-2016): Selective DC Surgery in the Current Era of Improving Resuscitation Practices}

The current stage of the innovation of DC surgery is characterized by questions about the effectiveness and safety of the procedure in modern trauma care and whether it should be used more selectively in the current era of improving resuscitation practices.

Although widely believed to be effective when appropriately indicated, no adequately controlled studies have been performed to evaluate DC surgery. ${ }^{3}$ Further, the procedure has been reported to be associated with several potentially severe complications (eg, intraabdominal abscesses/sepsis, massive ventral hernias, and enteroatmospheric fistulae), a substantial risk of readmission to hospital and need for subsequent surgical procedures, decreased physical and mental health, and a reduced quality of life among survivors. ${ }^{93-97}$ Studies have also recently reported data suggesting important variation in the use of DC surgery exists across trauma centers and that the procedure may be overused. ${ }^{98-100}$ Finally, some authors have suggested that clinical outcomes may improve with more selective use of DC surgery. ${ }^{98}$

Authors have also recently hypothesized that trauma resuscitation strategies that focus on rapid hemorrhage control, prevention and/or correction of coagulopathy, and avoidance of over-resuscitation with crystalloid fluids may reduce the need for DC surgery in the future. ${ }^{101-103}$ In 2003, Brohi et al ${ }^{104}$ conducted a retrospective cohort study of 1088 severely injured patients and observed that $33 \%$ had prolonged clotting times upon presentation to hospital that were independent of the volume of intravenous fluids administered. These authors suggested that there is "a common and clinically important acute traumatic coagulopathy" that occurs "before significant fluid administration, that may be attributable to the injury itself." 104 This was followed in 2007 by a retrospective cohort study by Borgman et $\mathrm{al}^{105}$ of 246 trauma patients requiring massive transfusion who were admitted to a combat support hospital in Iraq. Borgman et al ${ }^{105}$ reported that a high plasma: packed red blood cell (PRBC) ratio was independently associated with improved survival, primarily by decreasing death due to hemorrhage. These results were used by the United States Army's Institute of Surgical Research Conference to support development of the concept of "damage control resuscitation." 106 This group recommended immediate delivery of fresh frozen plasma, platelets, and PRBCs in a 1:1:1 ratio to injured patients requiring massive transfusion based on the rationale that a 1:1:1 ratio mimics the composition of whole blood. ${ }^{106,107}$ DC resuscitation is recommended to be delivered across the continuum of time-sensitive care for critically injured patients and therefore has influenced trauma resuscitation research and practice in the prehospital, Emergency Department, operating room, and ICU settings. Subsequent observational studies of DC resuscitation reported mixed yet frequently similar observations to that of Borgman et al. ${ }^{105}$ Most recently, the PROPPR randomized controlled trial compared a 1:1:1 and a 1:1:2 ratio of plasma: platelets: PRBCs and reported similar 24-hour and 30-day mortality for the 2 study groups. ${ }^{2}$ However, subgroup analyses suggested that more patients in the 1:1:1 group achieved hemostasis, and fewer experienced death due to exsanguination at 24 hours. $^{2}$ 


\section{CONCLUSIONS}

DC is an important innovation in trauma care and surgery during the last century. The history of DC provides a valuable illustration of surgical innovation, which highlights how a surgical technique that had previously been abandoned because of adverse events was subsequently adapted and readopted in response to an increased understanding of trauma patient physiology and changing patient injury patterns and trauma resuscitation practices. Studies are currently required to further delineate the role of DC surgery in the context of improving trauma resuscitation practices.

\section{ACKNOWLEDGMENTS}

Author Contributions Statement: Study concept and design, and development of search: D.J.R., C.G.B., D.A.Z., A.W.K., H.T.S. Conduct of search strategy: D.J.R. Identification of historical articles from the search strategy: D.J.R. Analysis and interpretation of historical articles: D.J.R., C.G.B., D.A.Z., A.W.K., H.T.S. Drafting of the manuscript: D.J.R. Identification of additional or missing historical references: D.V.F., E.E.M., R.R.I., C.E.L., T.C.F. Critical revision of the first draft of the manuscript with regard to historical events and innovation stages: D.V.F., E.E.M., R.R.I., C.E.L., T.C.F. Critical revision of subsequent versions of the manuscript for additional important intellectual content: D.J.R., C.G.B., T.C.F., E.E.M., R.R.I., C.E.L., T.C.F., D.A.Z., A.W.K., H.T.S. Study supervision: H.T.S. Final approval of the manuscript for submission for peer-review: D.J.R., C.G.B., D.V.F., E.E.M., R.R.I., C.E.L., T.C.F., D.A.Z., A.W.K., H.T.S.

\section{REFERENCES}

1. Roberts DJ, Bobrovitz N, Zygun DA, et al. Indications for use of damage control surgery and damage control interventions in civilian trauma patients a scoping review. J Trauma Acute Care Surg. 2015;78:1187-1196.

2. Holcomb JB, Tilley BC, Baraniuk S, et al. Transfusion of plasma, platelets, and red blood cells in a $1: 1: 1$ vs a $1: 1: 2$ ratio and mortality in patients with severe trauma: the PROPPR randomized clinical trial. JAMA. 2015;313:471 482 .

3. Roberts DJ, Zygun DA, Kirkpatrick AW, et al. A protocol for a scoping and qualitative study to identify and evaluate indications for damage control surgery and damage control interventions in civilian trauma patients. BMJ Open. 2014;4:e005634.

4. Barkun JS, Aronson JK, Feldman LS, et al. Evaluation and stages of surgical innovations. Lancet. 2009;374:1089-1096.

5. McCulloch P, Altman DG, Campbell WB, et al. No surgical innovation without evaluation: the IDEAL recommendations. Lancet. 2009;374:11051112.

6. Biffl WL, Spain DA, Reitsma AM, et al. Responsible development and application of surgical innovations: a position statement of the Society of University Surgeons. J Am Coll Surg. 2008;206:1204-1209.

7. Tilton BT II. Some considerations regarding wounds of the liver. Ann Surg. 1905;41:20-30.

8. Madding GF, Kennedy PA. Major Problems in Clinical Surgery: Trauma to the Liver. 2nd ed. Toronto, ON, Canada: W.B. Saunders Company; 1971.

9. Pringle JHV. Notes on the arrest of hepatic hemorrhage due to trauma. Ann Surg. 1908;48:541-549.

10. Schroeder WE. The progress of liver hemostasis-reports of cases (resection, sutures, etc.). Surg Gynecol Obstet. 1906;2:52-61.

11. Feliciano DV, Mattox KL, Burch JM, et al. Packing for control of hepatic hemorrhage. J Trauma. 1986;26:738-743.

12. Halstead WS. Ligature and suture material: the employment of fine silk in preference to catgut and the advantages of transfixion of tissues and vessels in control of hemorrhage - also an account of the introduction of gloves, guttapercha tissue and silver foil. JAMA. 1913;60:1119-1126.

13. Feliciano DV, Mattox KL, Jordan GL Jr. Intra-abdominal packing for control of hepatic hemorrhage: a reappraisal. J Trauma. 1981;21:285-290.

14. Madding GF, Lawrence KB, Kennedy PA. Forward surgery of the severely injured. Second Auxillary Surgical Group. 1942-1945;1:307.
15. Moore EE. Thomas G. Orr Memorial Lecture. Staged laparotomy for the hypothermia, acidosis, and coagulopathy syndrome. Am J Surg. 1996;172:405-410.

16. Crosthwait RW, Allen JE, Murga F, et al. The surgical management of 640 consecutive liver injuries in civilian practice. Surg Gynecol Obstet. 1962;114:650-654.

17. Morton JR, Roys GD, Bricker DL. The treatment of liver injuries. Surg Gynecol Obstet. 1972;134:298-302.

18. Walt AJ. The surgical management of hepatic trauma and its complications. Ann R Coll Surg Engl. 1969;45:319-339.

19. Madding GF. Injuries of the liver. AMA Arch Surg. 1955;70:748-756.

20. Lucas CE, Ledgerwood AM. Prospective evaluation of hemostatic techniques for liver injuries. J Trauma. 1976;16:442-451.

21. Elerding SC, Aragon GE, Moore EE. Fatal hepatic hemorrhage after trauma. Am J Surg. 1979;138:883-888.

22. Walt AJ. Founder's lecture: the mythology of hepatic trauma-or Babel revisited. Am J Surg. 1978;135:12-18.

23. Calne RY, McMaster P, Pentlow BD. The treatment of major liver trauma by primary packing with transfer of the patient for definitive treatment. $\mathrm{Br} \mathrm{J}$ Surg. 1979;66:338-339.

24. Clagett GP, Olsen WR. Non-mechanical hemorrhage in severe liver injury. Ann Surg. 1978;187:369-374.

25. Kashuk JL, Moore EE, Millikan JS, et al. Major abdominal vascular trauma-a unified approach. J Trauma. 1982;22:672-679.

26. Feliciano DV, Burch JM. Towel clips, silos, and heroic forms of wound closure. In: Maull KI, Cleveland HC, Feliciano DV, eds. Advances in Trauma and Critical Care, Vol. 6. Chicago: Mosby; 1991:231-251.

27. Harrigan C, Lucas CE, Ledgerwood AM. The effect of hemorrhagic shock on the clotting cascade in injured patients. J Trauma. 1989;29:1416-1421.

28. Shires T, Coln D, Carrico J, et al. Fluid therapy in hemorrhagic shock. Arch Surg. 1964;88:688-693.

29. McClelland RN, Shires GT, Baxter CR, et al. Balanced salt solution in the treatment of hemorrhagic shock. Studies in dogs. JAMA. 1967;199:830-834.

30. Stone HH, Strom PR, Mullins RJ. Management of the major coagulopathy with onset during laparotomy. Ann Surg. 1983;197:532-535.

31. Carmona RH, Peck DZ, Lim RC Jr. The role of packing and planned reoperation in severe hepatic trauma. J Trauma. 1984;24:779-784.

32. Ivatury RR, Nallathambi M, Gunduz Y, et al. Liver packing for uncontrolled hemorrhage: a reappraisal. J Trauma. 1986;26:744-753.

33. Baracco-Gandolfo V, Vidarte O, Baracco-Miller V, et al. Prolonged closed liver packing in severe hepatic trauma: experience with 36 patients. J Trauma. 1986;26:754-756.

34. Moore EE. Edgar J. Poth Lecture. Critical decisions in the management of hepatic trauma. Am J Surg. 1984;148:712-716.

35. Feliciano DV, Burch JM, Spjut-Patrinely V, et al. Abdominal gunshot wounds. An urban trauma center's experience with 300 consecutive patients. Ann Surg. 1988;208:362-370.

36. Feliciano DV, Pachter HL. Hepatic trauma revisited. Curr Probl Surg. 1989;26:459-524.

37. Eastlick L, Fogler RJ, Shaftan GW. Pancreaticoduodenectomy for trauma: delayed reconstruction: a case report. J Trauma. 1990;30:503-505.

38. Burch JM, Ortiz VB, Richardson RJ, et al. Abbreviated laparotomy and planned reoperation for critically injured patients. Ann Surg. 1992;215:476483

39. Rotondo MF, Schwab CW, McGonigal MD, et al. 'Damage control': an approach for improved survival in exsanguinating penetrating abdominal injury. J Trauma. 1993;35:375-382.

40. McGonigal MD, Cole J, Schwab CW, et al. Urban firearm deaths: a five-year perspective. J Trauma. 1993;35:532-536.

41. Wintemute GJ. The relationship between firearm design and firearm violence. Handguns in the 1990s. JAMA. 1996;275:1749-1753.

42. Surface Ship Survivability. Naval War Publications 3-20.31. Washington, DC: Department of Defense; 1996.

43. Hoey BA, Schwab CW. Damage control surgery. Scand J Surg. 2002;91:92103.

44. Rotondo MF, Zonies DH. The damage control sequence and underlying logic. Surg Clin North Am. 1997;77:761-777.

45. Johnson JW, Gracias VH, Schwab CW, et al. Evolution in damage control for exsanguinating penetrating abdominal injury. J Trauma. 2001;51:261-269.

46. Hirshberg A, Wall MJ Jr, Mattox KL. Planned reoperation for trauma: a two year experience with 124 consecutive patients. J Trauma. 1994;37:365-369. 
47. Poggetti RS, Moore EE, Moore FA, et al. Balloon tamponade for bilobar transfixing hepatic gunshot wounds. J Trauma. 1992;33:694-697.

48. Ball CG, Wyrzykowski AD, Nicholas JM, et al. A decade's experience with balloon catheter tamponade for the emergency control of hemorrhage. J Trauma. 2011;70:330-333.

49. Reilly PM, Rotondo MF, Carpenter JP, et al. Temporary vascular continuity during damage control: intraluminal shunting for proximal superior mesenteric artery injury. J Trauma. 1995;39:757-760.

50. Azimuddin K, Ivatury R, Porter J, et al. Damage control in a trauma patient with ureteric injury. J Trauma. 1997;43:977-979.

51. Coburn M. Damage control for urologic injuries. Surg Clin North Am. 1997;77:821-834.

52. Shapiro MB, Jenkins DH, Schwab CW, et al. Damage control: collective review. J Trauma. 2000;49:969-978.

53. Richards WO, Scovill W, Shin B, et al. Acute renal failure associated with increased intra-abdominal pressure. Ann Surg. 1983;197:183-187.

54. Kron IL, Harman PK, Nolan SP. The measurement of intra-abdominal pressure as a criterion for abdominal re-exploration. Ann Surg. 1984;199; 28-30.

55. Fietsam R Jr, Villalba M, Glover JL, et al. Intra-abdominal compartment syndrome as a complication of ruptured abdominal aortic aneurysm repair. Am Surg. 1989;55:396-402.

56. Balogh ZJ, Lumsdaine W, Moore EE, et al. Postinjury abdominal compartment syndrome: from recognition to prevention. Lancet. 2014:384:14661475 .

57. Burch JM, Moore EE, Moore FA, et al. The abdominal compartment syndrome. Surg Clin North Am. 1996;76:833-842.

58. Meldrum DR, Moore FA, Moore EE, et al. Prospective characterization and selective management of the abdominal compartment syndrome. Am J Surg. 1997; 174:667-672.

59. Smith PC, Tweddell JS, Bessey PQ. Alternative approaches to abdominal wound closure in severely injured patients with massive visceral edema. J Trauma. 1992;32:16-20.

60. Mayberry JC, Mullins RJ, Crass RA, et al. Prevention of abdominal compartment syndrome by absorbable mesh prosthesis closure. Arch Surg. 1997;132:957-961.

61. Shoemaker WC, Appel PL, Kram HB, et al. Prospective trial of supranormal values of survivors as therapeutic goals in high-risk surgical patients. Chest. 1988;94:1176-1186.

62. Balogh Z, McKinley BA, Cocanour CS, et al. Supranormal trauma resuscitation causes more cases of abdominal compartment syndrome. Arch Surg. 2003;138:637-642.

63. Morris JA Jr, Eddy VA, Blinman TA, et al. The staged celiotomy for trauma. Issues in unpacking and reconstruction. Ann Surg. 1993;217: 576-584.

64. Aprahamian C, Wittmann DH, Bergstein JM, et al. Temporary abdominal closure (TAC) for planned relaparotomy (etappenlavage) in trauma. $J$ Trauma. 1990;30:719-723.

65. Ivatury RR, Porter JM, Simon RJ, et al. Intra-abdominal hypertension after life-threatening penetrating abdominal trauma: prophylaxis, incidence, and clinical relevance to gastric mucosal $\mathrm{pH}$ and abdominal compartment syndrome. J Trauma. 1998;44:1016-1021.

66. Scott BG, Feanny MA, Hirshberg A. Early definitive closure of the open abdomen: a quiet revolution. Scand J Surg. 2005;94:9-14.

67. Fabian TC. Damage control in trauma: laparotomy wound management acute to chronic. Surg Clin North Am. 2007;87:73-93. vi.

68. Lucas CE. Torso challenges for the acute care surgeon: technical solutions for large torso defects. J Trauma Acute Care Surg. 2013;74:17-25.

69. Fabian TC, Croce MA, Pritchard FE, et al. Planned ventral hernia. Staged management for acute abdominal wall defects. Ann Surg. 1994;219:643650 .

70. Jernigan TW, Fabian TC, Croce MA, et al. Staged management of giant abdominal wall defects: acute and long-term results. Ann Surg. 2003;238:349-355.

71. Feliciano DV, Moore EE, Mattox KL. Trauma damage control. In: Mattox KL, Feliciano DV, Moore EE, eds. Trauma. 4th Ed., New York, N.Y: McGraw Hill; 2000:907-931.

72. Brock WB, Barker DE, Burns RP. Temporary closure of open abdominal wounds: the vacuum pack. Am Surg. 1995;61:30-35.

73. Schein M, Saadia R, Jamieson JR, et al. The 'sandwich technique' in the management of the open abdomen. Br J Surg. 1986;73:369-370.

74. Feliciano DV, Burch JM, Mattox KL, et al. Balloon catheter tamponade in cardiovascular wounds. Am J Surg. 1990;160:583-587.
75. Gilroy D, Lakhoo M, Charalambides D, et al. Control of life-threatening haemorrhage from the neck: a new indication for balloon tamponade. Injury. 1992;23:557-559.

76. Scalea TM, Mann R, Austin R, et al. Staged procedures for exsanguinating lower extremity trauma: an extension of a technique - case report. J Trauma. 1994;36:291-293.

77. Aucar JA, Hirshberg A. Damage control for vascular injuries. Surg Clin North Am. 1997;77:853-862.

78. Wall MJ Jr, Hirshberg A, Mattox KL. Pulmonary tractotomy with selective vascular ligation for penetrating injuries to the lung. Am J Surg 1994; 168:665-669.

79. Asensio JA, Demetriades D, Berne JD, et al. Stapled pulmonary tractotomy: a rapid way to control hemorrhage in penetrating pulmonary injuries. $J$ Am Coll Surg. 1997; 185:486-487.

80. Wagner JW, Obeid FN, Karmy-Jones RC, et al. Trauma pneumonectomy revisited: the role of simultaneously stapled pneumonectomy. J Trauma. 1996;40:590-594.

81. Wilson A, Wall MJ Jr, Maxson R, et al. The pulmonary hilum twist as a thoracic damage control procedure. Am J Surg. 2003; 186:49-52.

82. Scalea TM, Boswell SA, Scott JD, et al. External fixation as a bridge to intramedullary nailing for patients with multiple injuries and with femur fractures: damage control orthopedics. J Trauma. 2000;48:613-621.

83. Sutton E, Bochicchio GV, Bochicchio K, et al. Long term impact of damage control surgery: a preliminary prospective study. J Trauma. 2006;61:831834.

84. Miller PR, Meredith JW, Johnson JC, et al. Prospective evaluation of vacuum-assisted fascial closure after open abdomen: planned ventral hernia rate is substantially reduced. Ann Surg. 2004;239:608-614.

85. Petersson U, Acosta S, Bjorck M. Vacuum-assisted wound closure and meshmediated fascial traction-a novel technique for late closure of the open abdomen. World J Surg. 2007;31:2133-2137.

86. Malbrain ML, Cheatham ML, Kirkpatrick A, et al. Results from the International Conference of Experts on Intra-abdominal Hypertension and Abdominal Compartment Syndrome. I Definitions. Intensive Care Med. 2006;32:1722-1732.

87. Cheatham ML, Malbrain ML, Kirkpatrick A, et al. Results from the International Conference of Experts on Intra-abdominal Hypertension and Abdominal Compartment Syndrome. II. Recommendations. Intensive Care Med. 2007;33:951-962.

88. De Waele JJ, Cheatham ML, Malbrain ML, et al. Recommendations for research from the International Conference of Experts on Intra-abdominal Hypertension and Abdominal Compartment Syndrome. Acta Clin Belg. 2009;64:203-209.

89. Patel TH, Wenner KA, Price SA, et al. A U.S. Army Forward Surgical Team's experience in Operation Iraqi Freedom. J Trauma. 2004;57:201-207.

90. Moore EE, Knudson MM, Schwab CW, et al. Military-civilian collaboration in trauma care and the senior visiting surgeon program. $N$ Engl J Med. 2007;357:2723-2727.

91. Chambers LW, Green DJ, Gillingham BL, et al. The experience of the US Marine Corps' Surgical Shock Trauma Platoon with 417 operative combat casualties during a 12 month period of operation Iraqi Freedom. J Trauma. 2006;60:1155-1161.

92. Pape HC, Grimme K, Van Griensven M, et al. Impact of intramedullary instrumentation versus damage control for femoral fractures on immunoinflammatory parameters: prospective randomized analysis by the EPOFF Study Group. J Trauma. 2003;55:7-13.

93. Miller RS, Morris JA Jr, Diaz JJ Jr, et al. Complications after 344 damagecontrol open celiotomies. J Trauma. 2005;59:1365-1371.

94. Montalvo JA, Acosta JA, Rodriguez P, et al. Surgical complications and causes of death in trauma patients that require temporary abdominal closure. Am Surg. 2005;71:219-224.

95. Zarzaur BL, DiCocco JM, Shahan CP, et al. Quality of life after abdominal wall reconstruction following open abdomen. J Trauma. 2011;70:285-291.

96. Cheatham ML, Safcsak K, Llerena LE, et al. Long-term physical, mental, and functional consequences of abdominal decompression. J Trauma. 2004;56:237-241.

97. Cheatham ML, Safcsak K. Longterm impact of abdominal decompression: a prospective comparative analysis. J Am Coll Surg. 2008;207:573-579.

98. Higa G, Friese R, O'Keeffe T, et al. Damage control laparotomy: a vital tool once overused. J Trauma. 2010;69:53-59.

99. Cotton BA, Reddy N, Hatch QM, et al. Damage control resuscitation is associated with a reduction in resuscitation volumes and improvement in survival in 390 damage control laparotomy patients. Ann Surg. 2011;254:598-605. 
100. Roberts DJ, Bobrovitz N, Zygun DA, et al. Indications for use of damage control surgery in civilian trauma patients: a content analysis and expert appropriateness rating study. Ann Surg. 2016;263:1018-1027.

101. Schreiber MA. The beginning of the end for damage control surgery. $\mathrm{Br} J$ Surg. 2012;99(suppl 1):10-11.

102. Duchesne JC, McSwain NE Jr, Cotton BA, et al. Damage control resuscitation: the new face of damage control. J Trauma. 2010;69:976-990.

103. Holcomb JB, Jenkins D, Rhee P, et al. Damage control resuscitation: directly addressing the early coagulopathy of trauma. J Trauma. 2007;62: $307-310$.
104. Brohi K, Singh J, Heron M, et al. Acute traumatic coagulopathy. J Trauma. 2003;54:1127-1130

105. Borgman MA, Spinella PC, Perkins JG, et al. The ratio of blood products transfused affects mortality in patients receiving massive transfusions at a combat support hospital. J Trauma. 2007;63:805-813.

106. Holcomb JB, Hess JR. Early massive trauma transfusion: state of the art. J Trauma. 2006;60:S1-S2.

107. Rajasekhar A, Gowing R, Zarychanski R, et al. Survival of trauma patients after massive red blood cell transfusion using a high or low red blood cell to plasma transfusion ratio. Crit Care Med. 2011;39:1507-1513. 